\title{
RESENHA DA OBRA “DO FORMALISMO NO PROCESSO CIVIL": Proposta de um Formalismo-Valorativo
}

\author{
Nicola Picardi ${ }^{1}$ \\ Tradutor: Daniel Francisco Mitidiero ${ }^{2}$
}

\section{RESENHA PARA:}

OLIVEIRA, Carlos Alberto Alvaro de. Do formalismo no processo civil: proposta de um formalismovalorativo. 3. ed. São Paulo: Saraiva, 2009. 308 p.

1. A obra do conhecido processualista brasileiro, Carlos Alberto Alvaro de Oliveira, Do formalismo no processo civil: pro-posta de um fornalismo-valorativo, chega à $3^{\text {a }}$ edição. Trata-se de um estudo que teve uma larga difusão e influência na doutrina latino-americana do processo civil e que, a meu juízo, merece grande atenção também por parte do jurista europeu.

"O tema da forma oscila entre literatura e filosofia, entre direito e

1 Docente di Diritto processuale civile presso la Facoltà di Giurisprudenza della Luiss. Ordinario di Diritto processuale civile presso la Facoltà di Giurisprudenza dell'Università di Roma “La Sapienza”. Currículo: http://www.luiss.it/didattica/docenti/docentiCV3. php?cod=390. Endereço profissional: LUISS Guido Carli, Sede Centrale, Viale Pola, 12, Roma, Italia, 00198. Endereço eletrônico: npicardi@luiss.it.

2 Professor Adjunto da Pontifícia Universidade Católica do Rio Grande do Sul (PUCRS). Doutor em Direito pela UFRGS. Currículo: http://buscatextual.cnpq.br/ buscatextual/visualizacv.jsp?id=K4758191P6. Endereço profissional: Av. Ipiranga, 6681, Prédio 11, Sala 1030, Porto Alegre, RS, Brasil, CEP 90619-900. Endereço eletrônico: danielfcomitidiero@terra.com.br. 
psicologia: impõe-se encerrá-lo, fechálo no círculo do método normativo" (Irti, 1985, p. VII). Induvidosamente, a problemática do formalismo encontra um de seus principais setores de emersão no direito processual, que é entendido, segundo a opinião comum, como o "reino da forma". Mas, na maior parte das vezes, os processualistas se limitam a enunciar paráfrases, afirmando, por exemplo, que "forma quer dizer a parte extema [...] como o recipiente no qual a essência se contém: essa essência é a vontade" (Carnelutti, 1938, p. 16). Ao Professor De Oliveira, no entanto, cabe o mérito de ter abandonado as paráfrases e avançado uma proposta interpretativa que constitui o fio condutor da sua obra: o formalismo processual deve assumir o significado de um formalismo-valorativo, no sentido de que as formas processuais não devem ser excessivas enquanto fins em si mesmas, mas sim orientadas à tutela dos direitos fundamentais. $\mathrm{O}$ processo é concebido essencialmente como fenômeno cultural harmonizado aos valores. A justiça representa o valor final. A segurança jurídica e a efetividade da tutela jurisdicional (frequentemente em conflito entre si), como também a igualdade, representam os valores instrumentais. As técnicas empregadas de modo correto são os instrumentos para atingir os valores.

2. No primeiro capítulo, o autor lança as bases da própria tese por meio de uma acurada reconstrução histórica do formalismo processual, individualizando, conforme os períodos históricos tomados em consideração, as razões que justificaram a introdução de regras mais ou menos rígidas na disciplina do desenvolvimento do processo. A reconstrução leva em consideração a experiência jurídica romana no período das legis actionis, na qual o processo era caracterizado por um formalismo excessivo, de matriz simbólico-religiosa, para chegar à época atual, na qual múltiplos fatores de natureza econômica e social induzem a entender que as formas processuais devem permitir ao juiz desenvolver um papel ativo de cooperação com as partes, para se chegar a uma solução da controvérsia que seja o mais vizinha possível da realidade.

No segundo capítulo, o Prof. De Oliveira analisa os fundamentos do formalismo processual, distinguindo internamente esses, entre regras funcionais à tutela dos valores externos ao processo e normas precipuamente orientadas a uma maior eficiência processual. Sob o primeiro perfil, evidencia, em primeiro lugar, a instrumentalidade das formas processuais para evitar que o arbítrio do juiz determine iniquidades nos casos concretos nas decisões em casos semelhantes, O formalismo processual, por outro lado, destina-se a tutelar a confiança dos cidadãos, os quais, mediante as 
regras do processo - que por isso devem ser formuladas de modo claro - devem poder prever de modo razoável o seu resultado. Nessa perspectiva, revelam-se de particular importância, por exemplo, as normas destinadas a assegurar a uniformidade da jurisprudência. A tutela da paz social justifica, depois, as normas destinadas a tomar mais célere o processo, cuja função é eliminar o mais rápido possível o conflito criado entre as partes. Todavia, mesmo nesse caso não se deve chegar ao excesso de preferir uma decisão célere, mas injusta, porque em contraste com os direitos das partes. O autor sublinha, então, a fundamental importância do valor da efetividade da tutela, implicando que a parte vitoriosa possa obter, com o êxito do juízo, tudo quanto tem direito com base no direito substancial. Exatamente nessa perspectiva se insere a crescente importância da tutela cautelar, justificada pela vigência das regras que permitem obter ressarcimento em forma específica e não por último, é ressaltado, em consonância com os princípios estabelecidos pela Corte Europeia dos direitos do homem, que a efetividade da tutela passa também por resultados satisfatórios do processo executivo. $\mathrm{O}$ autor adverte, todavia, que também a persecução do objetivo da efetividade da tutela junsdicional deve ser virtuosa e não se traduzir, patologicamente, em uma disciplina processual orientada exclusivamente a uma boa perfor- mance, mas com pouca referência ao valor da justiça substancial. Em outros termos, deve-se procurar, por meio do balanceamento dos valores em conflito, alcançar um equilíbrio harmonioso que permita tutelar adequadamente os direitos do cidadão.

Sempre no âmbito do complexo segundo capítulo da monografia, o autor examina os princípios processuais destinados a tutelar a parte em face dos abusos do juiz e que constituem, na verdade, cânones fundamentais do processo equânime. Entre outros, lembra os princípios da imparcialidade do juiz, a submissão do juiz à lei, o princípio dispositivo e o direito de defesa. Por outro lado, adverte o autor que outras regras processuais, como a da preclusão ou a da ficta confessio, tendem sobretudo a limitar os poderes das partes com vistas a uma eficiente administração da justiça.

A obra prossegue com a ambiciosa análise das relações entre formalismo processual e princípios supremos garantidos pela Constituição brasileira, antes de todos, o princípio solenemente afirmado pela Constituição brasileira de que ninguém será privado da sua liberdade ou de seus bens sem o devido processo legal, princípio essencial do estado de direito, que compreende não apenas o direito de acesso ao juiz, como também a mais ampla garantia do processo equânime. Todavia, na disciplina positiva - 
adverte o autor - deve-se sempre procurar alcançar o justo equilíbrio entre o informalismo excessivo, que terminaria por atribuir ao juiz poderes arbitrários, e o formalismo excessivo, que poderia determinar uma extinção patológica do juízo antes da decisão de mérito por razões puramente formais. Entre as garantias do processo equânime é atribuída, assim, particular consideração ao direito de acesso ao juiz, do qual é efetuada uma atenta comparação entre os diversos modelos positivos vigentes, sobretudo no que concerne à tutela jurisdicional dos indivíduos em face dos poderes públicos. Na análise comparativa em questão, é atribuída particular relevância à atual experiência jurídica brasileira na qual também a tutela contra a atividade ilegítima da administração pública é assegurada pelo juiz ordinário, o qual goza de amplos poderes, podendo inclusive, impulsionar o processo, até em face da mesma. O compartilhável auspício do autor é que, diante de uma tal legislação, a praxe judiciária seja, também em concreto, sempre mais orientada a uma melhor tutela dos direitos fundamentais do cidadão. $\mathrm{O}$ ordenamento processual brasileiro, por outro lado, privilegia a concepção social do processo sancionada pela Constituição, ainda pela particular relevância atribuída à tutela dos interesses coletivos para a qual, recorda-se, é prevista a legitimação do Ministério Público, mostrando-se o julgado capaz de produzir efeitos ultra partes), e também pelos incisivos poderes, sobretudo de natureza interdital, conferidos ao juiz, de modo semelhante como ocorria com o pretor na experiência romana.

A última parte do segundo capítulo é dedicada, como anunciado, às normas que regulam o desenvolvimento do processo na finalidade precípua de tomá-lo célere e eficiente. De qualquer modo - põe em destaque o autor continua sendo essencial o respeito ao princípio do contraditório, elemento essencial do processo, entidade dinâmica e dialética na qual os atos de uma parte dependem dos atos da outra e da atividade do juiz. Por outro lado, as formas processuais não devem ser reguladas de modo a resultarem excessivas em relação às finalidades perseguidas ou ainda comprometerem o núcleo essencial dos direitos das partes. Em outros termos, sublinha o autor, o procedimento deve quanto possível adequar-se às exigências do caso concreto. Assim determinam, por exemplo, sob o perfil positivo, tanto o art. 244 do CPC brasileiro, quanto o art. 156 do CPC italiano, quando sancionam o princípio da instrumentalidade das formas processuais ao alcance de urna determinada finalidade (Brasil, 2005; Itália, 2004).

$\mathrm{Na}$ parte final do segundo capítulo, é examinada a incidência das diferentes técnicas processuais 
sobre a tutela dos direitos. Em tal perspectiva, o autor evidencia, antes de tudo, a particular idoneidade da tutela em forma específica em relação àquela por equivalente para garantir as situações jurídicas subjetivas e a importante função desenvolvida pelas formas de execução indireta, como as asíreintes. O capítulo se encerra, outrossim, com uma reflexão acerca da oportunidade de introduzir, também no sistema processual brasileiro, um juízo especial, eventualmente eleito, com incisivos poderes conciliadores para a resolução das controvérsias de pequeno valor econômico.

3. O terceiro capítulo é dedicado ao formalismo processual em relação aos atores que cooperam para o desenvolvimento do processo, ou seja, o juiz e as partes. Com relação à posição do juiz, a análise expõe uma arguta consideração: existe uma relação inversamente proporcional entre os poderes das partes e do juiz, assim como entre formalismo processual e discricionariedade do juiz. Em tal sentido, as normas processuais podem incidir, sobretudo, sobre a amplitude dos poderes do juiz na investigação e apreciação dos fatos, sendo pacífico de qualquer modo que pertença ao juiz, em virtude do principio lura novil curia, individualizar a norma de direito e aplicá-la no caso concreto. Partindo dessa premissa, o autor evidencia que o processo liberal se caracterizava, do início ao fim, pelo monopólio das partes, em coerência com uma concepção individualista do processo, compreendido como instrumento voltado exclusivamente à tutela dos direitos individuais. Corolário de dita concepção é o papel eminentemente passivo do juiz na investigação da verdade. Em contrapartida, nos sistemas processuais que expressam uma concepção publicista do processo, o juiz goza de poderes significativos, exercíveis também de ofício, na investigação da "realidade objetiva". Em face desses modelos opostos, o autor atribui significativa relevância, na própria reconstrução histórica, à elaboração de Klein, segundo a qual é necessário que sejam atribuídos ao juiz poderes tendentes a reequilibrar os poderes das partes, em favor da menos favorecida, em razão de fatores econômicos ou sociais. O autor parte exatamente dessa intuição para desenvolver a sua proposta interpretativa com vistas ao papel que o juiz é chamado atualmente a desenvolver, ou seja, a colaborar ativamente com as partes na investigação da verdade, entendida como correta reconstrução dos fatos controversos, para uma decisão que se distancie o menos possível do real. A análise prossegue evidenciando, sempre em perspectiva histórica, a passagem do sistema medieval da prova legal e do livre convencimento das partes por parte do juiz. Princípio, demonstra o autor, que deve ser avalizado na medida 
em que a prova tenha sido formada no contraditório entre as partes, o procedimento tenha sido público e, sobretudo, motivada a sentença com base em critérios lógicos depois da realização da prova. Em outros termos, o livre convencimento do juiz deve ser sustentado por cânones racionais e não se traduzir em uma íntima convicção, isto é, em um juízo intuitivo de pura equidade: daí deriva que as regras a aplicar na valoração das provas devem ser conforme às máximas de experiência e, mais em geral, aos valores econômicos e sociais relevantes em um determinado momento histórico. Segue o exame do princípio lura novil curia, o qual encontra atualmente aplicação também com relação ao direito estrangeiro: a fim de evitar que tal princípio se torne um instrumento autoritário e de qualquer modo oportuno, segundo o autor, que o juiz e as partes cooperem entre si também na inviduação da norma de direito aplicável no caso concreto.

A obra prossegue com a análise de como as regras formais do processo limitam os poderes processuais das partes. O autor salienta que, no particular, assume, antes de tudo, relevância o princípio da preclusão, que implica a distinção do processo em fases e se contrapõe ao princípio da liberdade processual, em regra aplicado nos processos caracterizados por maior oralidade, imediatidade e concentração. A aplicação concreta do princípio da eventualidade pode comportar alguns problemas a respeito da garantia do contraditório, em razão de que uma parte poderia ter interesse em efetuar algumas afirmações ou em se defender apenas quando a outra parte abriu as suas próprias cartas: todavia, o autor nota que também a extrema liberdade processual, que caracterizou, por exemplo, o processo civil italiano da contrarrefoma de 1950 até a Lei ${ }^{\circ}$ 353, de 23 de no-vembro de 1990, o qual não produziu resultados positivos em termos de eficiência processual. Em realidade, segundo o autor, a matéria deveria ser regulada tendo presente a situação cultural do povo, o seu nível de litigiosidade, a aptidão dos juízes e advogados e, em todo caso, permitindo-se às partes modificar a demanda depois da primeira audiência, produzir sempre novos documentos, e também efetuar, em sede recursal, novas alegações se isso não tiver sido possível em razão de força maior. Com referência aos termos processuais peremptórios, observa o autor que deveriam ser fixados pela lei de modo racional e uniforme, permitindo-se em casos excepcionais a intervenção do juiz para ajustar-lhe a medida.

O capítulo quarto é dedicado às relações entre formalismo e justiça, ou seja, à possibilidade de que as regras formais do processo comprometam uma eficaz tutela do direito 
substancial exitoso. Na aplicação do direito, segundo o autor, a problemática de maior relevo é adaptar o caso concreto à regra geral: trata-se de uma atividade inevitavelmente criativa, visto que o legislador não pode prever todas as hipóteses possíveis, portanto, em algumas hipóteses, caberá ao juiz preencher a lacuna legislativa. De outra parte, a antinomia entre formalismo e justiça se realiza quando a parte que tem razão do ponto de vista do direito substancial resulta sucumbente por motivos puramente formais. A esse respeito, sublinha o autor, o direito brasileiro contém regras que, em via de princípio, eliminam as consequências negativas do formalismo excessivo, procurando, assim, resolver a antinomia mencionada. Por exemplo, a Constituição brasileira reconhece o princípio da igualdade, o princípio do contraditório, o direito de defesa e impõe ao juiz motivar as próprias decisões: o respeito aos ditos princípios deveria impedir escolhas irracionais e arbitrárias. Também no âmbito da legislação ordinária é atribuída ao juiz uma ampla liberdade, de modo a evitar que seja constrangido a decidir em contraste com a própria consciência por razões meramente formais.

Na continuação da análise, o autor salienta que a distância entre a abstração da norma processual e sua aplicação nos casos concretos pode ser reduzida empregando-se o instrumento da equidade. Com efeito, sobretudo diante de conceitos jurídicos indeterminados, a equidade, que deve corresponder aos valores vigentes na sociedade, pode desenvolver uma essencial função integrativa.

O quinto e último capítulo sintetiza o conteúdo dos capítulos precedentes e resume a tese do autor.

\section{REFERÊNCIAS}

BRASIL. Código de processo civil. São Paulo: Vértice, 2005. 480 p. CARNELUTTI, Francesco [18791965]. Sistema di diritto processuale civile. Padova: CEDAM, 1938. v. 2.
IRTI, Natalino. Idola libertatis: tre esercizi sul formalismo giuridico. Milano: Giuffrè, 1985. 96 p.

ITÁLIA. Codice di procedura civile. Milano: Giuffrè, 2004. 982 p. 